\title{
“TOWARDS GAMELAN POP”
}

\author{
Kenny Prehara \\ Penciptaan Seni Program Studi S2 Pascasarjana ISI Surakarta \\ Email: ken2prehara@gmail.com \\ Rahayu Supanggah \\ ISI Surakarta
}

\begin{abstract}
ABSTRAK
“Towards Gamelan Pop” adalah karya seni musik yang lahir akibat bentuk permasalahan yang sedang populer saat ini, misalnya korupsi, kurangnya kepedulian terhadap lingkungan hidup, radikalisme, tindak pelanggaran hukum, dan kerusakan moral. Fenomena tersebut dikaitkan dengan bentuk musik pop yang sedang diminati oleh banyak kalangan masyarakat. "Towards Gamelan Pop" mengangkat kisah legenda setempat di daerah Kompleks Candi Gedong Songo yaitu Kisah Ramayana dengan tujuan menarik generasi muda untuk mencintai kesenian tradisi nusantara. Karya musik ini memadukan instrumen gamelan dengan gaya bernyanyi pop dan diperankan oleh 6 tokoh, yaitu Rama, Shinta, Rahwana, Wibisana, Hanoman, dan Semar. Karya musik ini dipentaskan di Kompleks Candi Gedong Songo dengan durasi 60 menit yang terbagi dalam sebelas karya lagu, yaitu Rimba Raya, Aku, Satu, Penjara Emas, Hanoman Obong, Petuah yang Dianggap Sampah, Eling lan Waspada, Gerhanamu, Impas, Mandi Api, dan Sigaraning nyawa.
\end{abstract}

Kata kunci : populer, pop, Kisah Ramayana, generasi muda, gamelan.

\begin{abstract}
"Towards Gamelan Pop" is the musical art work form due to the problems that are popular today, such as corruption, the lack of concern towards the environment, radicalism, acts of lawlessness, and moral damage. These phenomena are associated to a form of pop music that is in demand by many people in the community. "Towards Gamelan Pop" lifts the local legends from the Gedong Songo temple complex that is the story of Ramayana, which its purpose is to attract the younger generation to love the

traditional arts of the archipelago. This musical work blends gamelan instruments with pop singing style and performed by six characters, namely Rama, Shinta, Rahwana, Wibisana, Hanoman, and Semar. This musical work is staged in the Gedong Songo complex with a duration of 60 minutes divided into eleven song parts, namely "Rimba Raya" (the Great Jungle), "Aku" (I), "Satu" (One), "Penjara Emas" (the Golden Prison), "Hanoman Obong" (Ignited Hanoman), "Petuah yang Dianggap Sampah" (Unconsidered Wisdom), "Eling lan Waspada" (Keep in Mind and Alert), "Gerhanamu" (Your Eclipse), "Impas" (Breakeven), "Mandi Api" (Bathe in Flames), and "Sigaraning Nyawa" (Soulmate).
\end{abstract}

Keywords: popular, pop, Ramayana Legend, young generation, gamelan.

\section{A. Pendahuluan}

Banyak sekali permasalahan yang sedang populer di negara ini sebagai contoh adalah permasalahan tentang korupsi, kurangnya kepedulian terhadap lingkungan hidup, radikalisme, tindak pelanggaran hukum serta kerusakan moral, dan masih banyak lagi. Munculnya permasalahan tersebut akibat dari kalangan masyarakat umum sampai dengan kalangan petinggi yang tidak bekerja sesuai dengan kewajibannya.

Mengutamakan kepentingan pribadi atau golongan baik dari kalangan masyarakat umum maupun kalangan petinggi merupakan sumber dari permasalahan yang dijabarkan di atas. Pelaku atau orang yang mengutamakan kepentingan pribadi akan menghalalkan segala cara untuk mencapai tujuannya, sehingga dalam kenyataannya, banyak perilaku yang menyimpang aturan dan hukum yang berlaku. Banyak sekali pelaku-pelaku tersebut tidak tersentuh oleh hukum akibat lemahnya hukum di negara ini.

Salah satu kesenian yang sedang populer saat ini adalah musik pop. Musik pop menurut Das Grosse Lexikon der Musik (dalam Karl-Edmund,2009:166 ) istilah pop berasal dari kata Inggris popular music $=$ musik kerakyatan. Namun kurang tepat bila istilah musik pop diturunkan dari musik rakyat dalam arti yang sesungguhnya, yakni sebagai lagu yang lahir 
secara anonim dan diwariskan dalam rakyat.

Cerita pewayangan dan gamelan adalah salah satu contoh budaya nenek moyang yang menjadi identitas negara kita yang pantas untuk dilestarikan.

Dengan mengkolaborasikan kesenian nusantara dengan musik pop diharapkan para generasi muda semakin tertarik. Selain itu, diharapkan dengan musik populer ini dapat mengkritik permasalahan yang sedang populer saat ini di bidang politik maupun lingkungan sosial.

Dengan mengkaitkan antara permasalahan populer dengan kesenian yang sedang populer maka lahirlah karya seni dengan judul "Towards Gamelan Pop". Akan tetapi karya seni ini tidak terlepas dari kisah dan budaya yang kita punya. Karya ini mengangkat sebuah kisah legenda yaitu Kisah Ramayana yang mengambil bagian dari penculikan Shinta sampai dengan bertemunya kembali antara Rama dan Shinta. Alur cerita dalam karya ini sama dengan alur cerita Kisah Ramayana hanya saja makna yang disampaikan adalah tentang kehidupan sekarang. Karya seni musik ini ditampilkan di Kompleks Candi Gedong Songo yang mempunyai kesesuaian kisah legenda yaitu Kisah Ramayana.

"Towards Gamelan Pop" menyajikan sebelas karya lagu dengan gaya pop dan diiringi dengan seperangkat gamelan berlaras pelog tanpa menggunakan seperangkat alat band seperti pada campursari. Sebelas karya lagu mempunyai makna yang berbeda-beda yang berhubungan dengan kondisi saat ini. Sebelas karya lagu itu dinyanyikan oleh enam penyanyi yang sekaligus memerankan tokoh dan karakter dalam Kisah Ramayana. Tokoh itu adalah Rama, Shinta, Rahwana, Wibisana, Hanoman, dan Semar. Setiap tokoh mempunyai karakter yang berbeda-beda. Karya seni musik ini menekankan pada bagian lirik karena menurut pengkarya lirik adalah bahasa oral yang mudah untuk dipahami dan dicermati bagi pendengarnya.

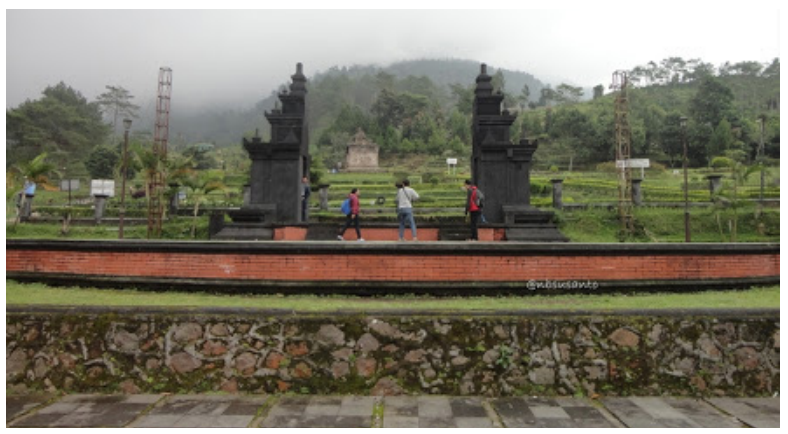

Foto 1. Panggung pementasan di Kompleks Candi Gedong Songo

\section{Gagasan Isi}

Gagasan yang ingin disampaikan dari karya seni musik "Towards Gamelan Pop" ini adalah penyampaian pesan moral dalam Kisah Ramayana yang disajikan dalam sebelas lagu, yaitu:

\section{1. "Rimba raya"}

Rimba raya mempunyai arti hutan alami dengan pohon-besar yang tumbuh. Garapan ini menggambarkan keadaan hutan yang indah, penuh dengan tumbuhan yang subur, dan binatang yang hidup secara alami. Menyadari bahwa kekayaan alam harus disyukuri dan dijaga ekosistemnya.

\section{2. "Aku"}

Kata "Aku" pada judul lagu ini diartikan sebagai penggambaran makhluk yang menganggap dirinya paling hebat dalam hal apapun. Memamerkan ilmu, harta, dan kekuasaan. Pemimpin yang seharusnya rendah hati malah bersikap sombong yang tidak perlu dilakukan.

\section{3. "Satu"}

Cinta dalam konteks berpasangan adalah saling membutuhkan. Hal ini harus diperjuangkan jika kedua belah pihak memilikinya dan berkomitmen menjaganya. Pengorbanan adalah hal yang wajar untuk dilakukan walau ada hal yang merintangi hubungan tersebut dikarenakan satu sama lainnya tidak bisa hidup bahagia jika tidak hidup bersama. Kesetiaan adalah tidak melanggar janji atau berkhianat, saat keadaan senang mudah menjadi setia tapi disaat memburuk disinilah ujian kesetiaan sesungguhnya.

\section{4. "Penjara emas"}

Penjara adalah tempat manusia dikurung dan dibatasi kebebasannya. Emas adalah batu mulia yang dianggap mempunyai nilai keindahan dan biasanya digunakan untuk perhiasan. Penjara emas di sini mempunyai arti sebagus dan semewah apapun fasilitas yang diberikan tidaklah membuat bahagia apabila tidak boleh bepergian ditempat lain yang diinginkan.

\section{5. "Hanoman obong"}

Keberanian merupakan suatu sikap yang sangat dibutuhkan dalam hidup. Suatu contoh dalam kehidupan masyarakat sekarang ini sebagian orang memilih diam pada saat melihat ketidakadilan bahkan ketika ketidakadilan itu menimpa pada 
dirinya sendiri. Dikarenakan kekuatan kejahatan yang bisa mengancam keselamatan sebagian orang takut dengan resiko itu. Sifat berani karena benar sangat diperlukan demi mencegah perkembangan kejahatan dan resiko bisa diminimalisir dengan strategi yang cerdik.

\section{6. "Petuah yang dianggap sampah"}

Nasihat yang baik tidak selalu diterima dengan baik. Dalam kenyataan tidak banyak orang yang mau mendengar nasihat yang benar. Sebagian orang lebih senang mendengar pemikiran yang sependapat walaupun itu salah, bahkan seseorang bisa membenci penasihat bijak dikarenakan pendapat yang bersebrangan.

\section{7. "Eling lan waspada"}

Sikap eling lan waspada berguna sebagai pencegahan terhadap kecerobohan dan kelalaian yang sering manusia lakukan. Dalam melakukan suatu tindakan sebaiknya kita pikirkan akibat dan manfaatnya. Jangan sampai tindakan itu berbuah penyesalan. Suatu contoh, dalam kehidupan saat ini banyak konflik antara pendukung calon pejabat atau partai politik yang mengakibatkan bentrokan bahkan sampai berujung pada kematian. Harusnya para pendukung tahu persis apa yang mereka bela, kepentingan bersama ataukah kepentingan pribadi. Pemimpin yang pantas dipatuhi adalah pemimpin yang mampu menyejahterakan dan memberi rasa aman, bukan pemimpin yang memprioritaskan kepentingan pribadi.

\section{8. "Gerhanamu"}

Gerhana (masa kegelapan) akan datang apabila pemimpin tidak bisa mengendalikan hawa nafsu dan tidak menghalalkan segala cara untuk mendapatkan sesuatu yang diinginkan. Termasuk merampas hak orang lain, karena walaupun yang berhak tidak memintanya tetap saja hasil rampasan itu tidak bermakna.

\section{9. "Impas"}

Kita akan menuai apa yang kita tanam, jika kita menanam kebaikan kita akan menuai kebaikan sebaliknya jika kita menuai keburukan kita akan mendapatkan hukuman. Semua yang terjadi psti berkaitan satu sama lainnya. Sejatinya tidak ada baik dan buruk semua itu adalah penghakiman dari hasil perbuatan yang kita sadari.

\section{0. "Mandi api"}

Dalam situasi tertentu kata-kata tidak cukup untuk dipercaya harus ada pembuktian yang dilakukan jadi tidak perlu takut dengan resiko apapun jika memang yang dilakukan sudah benar. Tidak perlu memikirkan tuduhan negatif orang lain apabila kita tidak melakukan apa yang mereka tuduhkan.

\section{1. "Sigaraning nyawa"}

Salah satu kebahagiaan adalah menemukan seorang "garwo". Yang dimaksud 'garwo" adalah pasangan hidup. Dalam falsafah Jawa "garwo" adalah singkatan dari sigaraning nyawa atau separuh nyawa. Dalam proses pencapaiannya dibutuhkan konsistensi kesetiaan, pengorbanan, dan keberanian. Jangan menyerah dalam memperjuangkan hal itu karena sesuatu yang didapat secara cuma-cuma tidak berarti apa-apa.

\section{Gagasan Garap dan Bentuk}

Seperti kita ketahui bersama, bahwa dalam dunia kesenian istilah "konsep garap" (di Jawa maupun Indonesia pada umumnya) bukan hanya digunakan dalam bidang karawitan. Konsep garap hampir diberlakukan dan/atau digunakan pada berbagai cabang dan jenis seni yang lain, terutama pada seni pertunjukan dan jenis-jenis kesenian lainnya yang dalam proses kerjanya melibatkan dua atau lebih pihak (Rahayu Supanggah, 2009:3).

Garapan karya seni musik “Towards Gamelan Pop" yang terlahir dari respon terhadap berbagai fenomena disajikan dalam bentuk karya lagu yang berjumlah sebelas karya lagu. Dalam karya seni ini menggunakan seperangkat gamelan berlaras pelog yang terdiri dari kendang, bonang barung, saron, demung, peking, kenong, slenthem, gong, dan kempul. Pengkarya memilih menggunakan seperangkat gamelan berlaras pelog karena mampu mengekspresikan berbagai macam suasana yang dibutuhkan dan gamelan berlaras pelog lebih dekat dengan tangga nada diatonis.

Seperangkat gamelan berlaras pelog dikolaborasikan dengan vokal dengan gaya pop. Pada vokal gaya pop menekankan pada bagian lirik yang mudah didengarkan dan dipahami pendengar dan dipadukan dengan seperangkat gamelan tersebut. Teknik penggarapan komposisi menggunakan teknik pengolahan motif, yaitu ulangan harafiah, sekuens, pembesaran dan pemerkecilan interval, pembalikan, pembesaran dan pemerkecilan nilai 
nada. Perpaduan harmoni gamelan berlaras pelog dengan vokal pop teknik SATB (Sopran, Alto, Tenor, dan Bass) menggunakan pendekatan frekuensi sedekat mungkin. Selain itu didukung layar yang berisi lirik lagu sebagai penguat syair yang dinyanyikan penyanyi dan seperangkat alat tata cahaya yang akan disesuaikan dengan nuansa, ritme, dan dinamika dari setiap karya lagu yang bertujuan untuk membangun suasana dan imajinasi kepada penonton. Sebelas karya lagu tersebut disajikan oleh enam penyanyi yang setiap penyanyi mewakili satu tokoh dalam Kisah Ramayana dan didukung dengan kostum yang sesuai dengan karakternya.

Karya seni musik "Towards Gamelan Pop" secara struktural terbagi menjadi sebelas karya lagu, dari kesemua karya lagu tersebut saling berkaitan sesuai Kisah Ramayana. Penjelasan konsep garap karya ini adalah sebagai berikut:

\section{1. "Rimba Raya"}

Gagasan garap karya ini ingin menghadirkan suasana damai, ceria, dan sejuk alami di sebuah hutan. Instrumen yang digunakan untuk menggarap rhythm adalah slenthem, kendang, demung, melodi menggunakan instrumen bonang barung, gong, kenong, peking, dan saron. Dalam adegan ini tokoh yang berperan adalah Shinta dengan karakter warna suara yang merdu. Pengolahan yang dilakukan adalah permainan ritmis yang menghadirkan ekspresi bahagia. Lirik lagu berisi tentang rasa syukur dan menyadari kekayaan alam itu indah. Dalam lagu ini terbagi menjadi tiga bagian, yaitu intro, verse, chorus. Kostum yang digunakan adalah gaun sesuai dengan karakter Shinta yang cantik dan anggun.

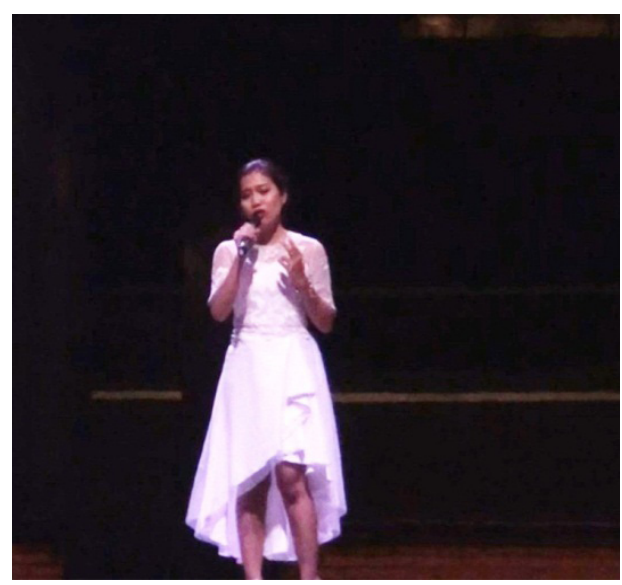

Foto 2. Shinta

\section{2. "Aku"}

Garapan karya "Aku" ingin menghadirkan suasana yang menggambarkan sifat angkuh dengan karakter vokal Rock dan didukung kostum yang sesuai agar lebih terlihat cadas. Dalam karya ini rhythm menggunakan instrumen demung, kendang, melodi menggunakan gong, peking, dan saron. Dalam adegan ini yang berperan adalah Rahwana pada saat ia akan menculik Shinta. Lirik berisi tentang kesombongan Rahwana yang selalu merasa paling hebat. Dalam lagu ini terbagi menjadi intro, verse, chorus.

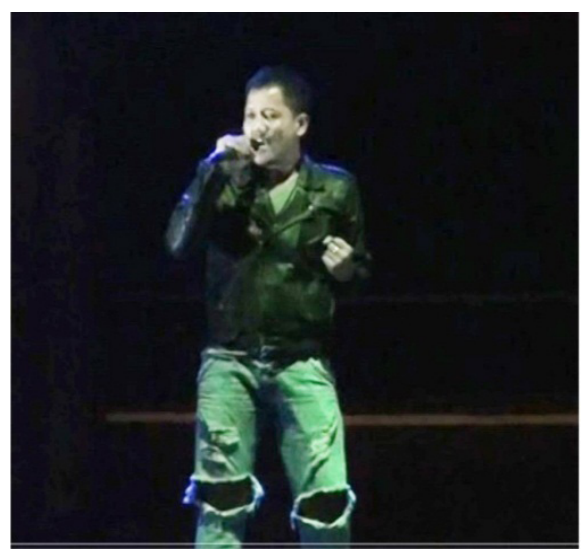

Foto 3. Rahwana

\section{3. "Satu"}

Suasana yang dihadirkan dalam karya ini adalah sedih. Kesedihan itu digambarkan seorang Rama sebagai ksatria tangguh yang merasa kehilangan Shinta. Dalam lagu ini bernuansa sedih namun tetap bertempo cepat dengan gaya bernyanyi yang lantang agar tidak meninggalkan karakter dari Seorang Rama. Instrumen yang digunakan untuk menggarap rhythm adalah demung, kenong, saron, dan kendang, melodi menggunakan peking dan saron. Tokoh yang berperan dalam adegan ini adalah Rama dalam perjalanan mencari Shinta. Tokoh Rama didukung dengan penggunaan kostum yang casual sesuai dengan karakter seorang pangeran tampan dan elegan. Dalam lagu ini terbagi menjadi tiga bagian, yaitu intro, verse, chorus. 


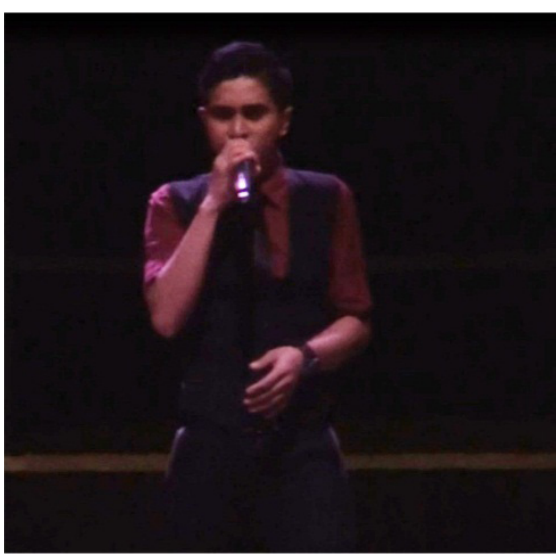

Foto 4. Rama

4. "Penjara Emas"

Adegan ini sebenarnya menggambarkan suasana hati yang kecewa namun ditunjukkan dengan ekpresi yang tegar. Tokoh yang berperan adalah Shinta yang berada di Taman Asoka pada saat Hanoman mengetahui keberadaannya. Instrumen yang digunakan untuk menggarap rhythm adalah demung, kendang dan slenthem, melodi menggunakan bonang barung, demung, gong, peking, saron. Ekspresi kesedihan diungkapkan dengan isi lirik lirik lagu dan bertempo pelan yang terbagi menjai tiga bagian, yaitu intro, verse, chorus.

\section{5. "Hanoman obong"}

Tokoh yang berperan adalah Hanoman yang tertangkap oleh Indrajid (putra Rahwana). Suasana yang dihadirkan adalah tegang. Dalam lagu ini pengkarya sengaja menempatkan lagu ini sebagai gimmick, hal yang dilakukan adalah gerakan-gerakan penyanyi yang layaknya Hanoman. Instrumen yang digunakan untuk menggarap rhythm adalah kendang, demung, saron, melodi menggunakan bonang barung, demung, gong, kempul, peking, saron, kenong. Pengolahan yang dilakukan dalam karya ini adalah dengan permainan dinamik yang ekspresif, didukung dengan pencahayaan yang sesuai ritme dan suasana lagu. Terbagi dalam tiga bagian lagu, yaitu intro, verse, chorus.

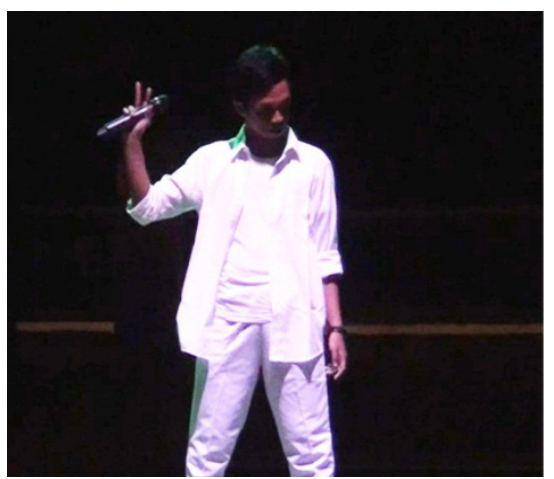

Foto 5. Hanoman

6. "Petuah yang dianggap sampah"

Suasana yang dihadirkan adalah kekecewaan Wibisana terhadap Rahwana pada waktu nasihatnya ditolak. Karaker vokal dalam lagu ini tegas sebagai gambaran kekesalan raksasa terhadap penolakan nasihatnya. Kostum yang digunakan hampir sama dengan Rahwana bedanya hanya pada penggunaan warna. Instrumen yang digunakan untuk menggarap rhythm adalah slenthem, kendang dan demung, melodi menggunakan bonang barung, demung, gong, kempul, kenong, peking, dan saron. Terbagi dalam tiga bagian lagu intro, verse, chorus.

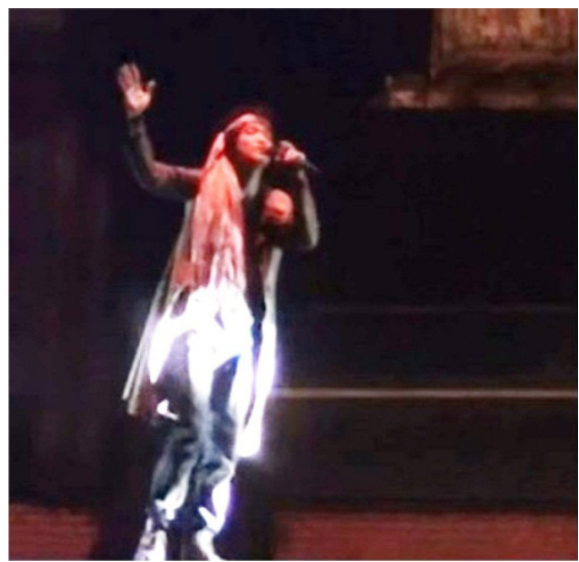

Foto 6. Wibisana

7. "Eling lan waspada"

Dalam karya ini suasana yang dihadirkan adalah lucu dengan tokoh yang berperan adalah Semar. Tokoh Semar dalam karya ini bernyanyi dengan gesture dan gaya bernyanyi yang jenaka, didukung dengan kostum sorjan yang melambangkan rakyat jawa sederhana. Instrumen yang digunakanuntuk menggarap rhythm, yaitu demung dan kendang, melodi menggunakan adalah bonang barung, demung, peking, dan saron. Dalam karya ini terbagi dalam tiga bagian lagu, yaitu intro, verse, chorus. 


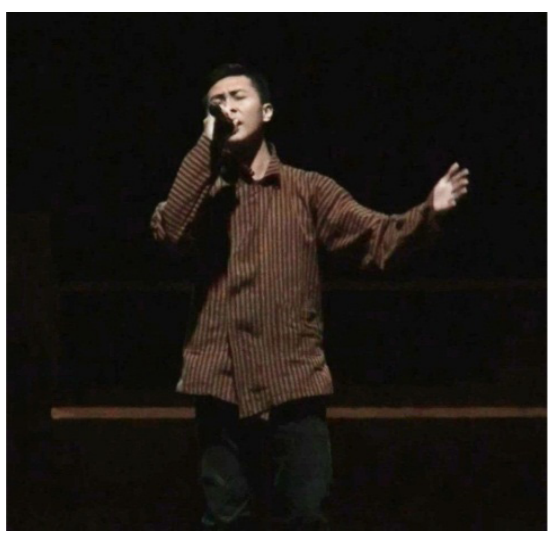

Foto 7. Semar

\section{8. "Gerhanamu"}

Suasana yang dihadirkan adalah tegang. Dalam adegan ini Rama menantang Rahwana. Instrumen yang digunakan untuk menggarap rhythm adalah kendang, saron, dan demung, melodi menggunakan bonang barung, demung, gong, kenong, peking, dan saron. Pengolahan yang dilakukan adalah penggunaan backing vocal yang mengiringi nyanyian Rama sehingga memperkuat nuansa. Terbagi dalam tiga bagian lagu, yaitu intro, verse, chorus.

\section{9. "Impas"}

Pada adegan ini diperankan oleh Rama. Suasana yang dihadirkan dalam adegan ini adalah tegang. Instrumen yang digunakan untuk menggarap rhythm adalah kendang, saron, dan demung, melodi menggunakan bonang barung, bonang penerus, demung, gong, peking, dan saron. Pada lagu ini diperkuat dengan backing vocal. Lagu ini terbagi dalam tiga bagian, yaitu intro, verse, chorus.

\section{0. "Mandi api"}

Tokoh yang berperan adalah Shinta yang diragukan kesuciannya oleh Rama dan harus membuktikan kesuciannya sehingga menghadirkan suasana sedih. Menggunakan instrumen slenthem, peking, demung menggarap rhythm. Lagu ini bertempo yang lambat untuk memperkuat suasana sedih. Dalam lagu ini terbagi dalam empat bagian yaitu intro, verse, bridge, dan chorus.

\section{1. "Sigaraning nyawa"}

Menggambarkan suasana kebahagiaan antara Rama dan Shinta karena sudah bertemu kembali dalam keadaan utuh. Dalam lagu ini rhythm menggunakan instrument adalah kendang, demung dan saron, melodi menggunakan bonang barung, demung, gong, dan saron. Lagu ini terbagi menjadi empat bagian, yaitu intro, verse, chorus, dan bridge.

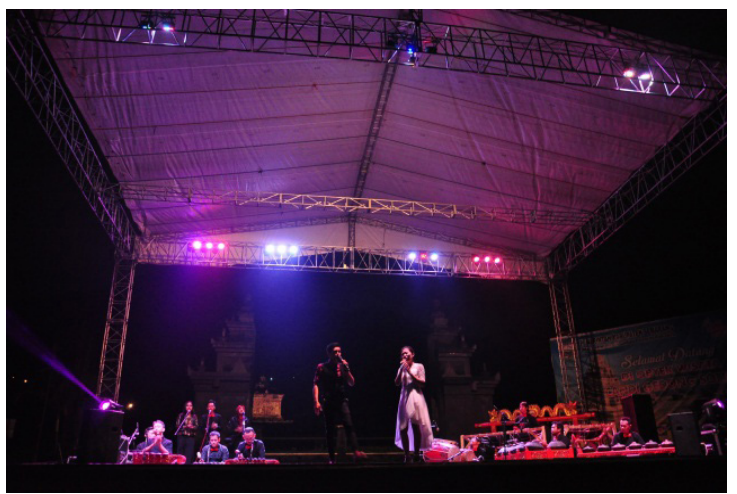

Foto 8. Rama dan Shinta

\section{Deskripsi Karya}

Dalam karya seni musik ini disajikan dalam sebelas lagu dengan genre pop dengan durasi, lirik, dan notasi sebagai berikut :

1. "Rimba raya"

Tempo : $105 \mathrm{bpm}$

Sukat $\quad: 4 / 4$

Durasi : 6.50 menit

Lirik

Verse 1

Burung-burung tak malu berbunyi

Kala mentari sambut sang pagi

Pohon dan rumput tak enggan bersemi

Kala sang embun mulai membasahi

Chorus

Semilir bayu belai kalbu

Dekapan alam hangatkan jiwa

Verse 2

Awan putih berkejaran dilangit biru

Aroma wangi tanah subur di bukit hijau

Berdesir irama daun tertiup angin

Bersentuh padu cinta harmoni

Kembali ke chorus

2."Aku"

Tempo : $90 \mathrm{bpm}$

Sukat $\quad: 4 / 4$

Durasi $\quad: 5.56$ menit

Lirik :

Verse 1

Setiap perkatanku adalah kepastian

Setiap gerakanku adalah kekuatan 
Setiap kemauanku adalah keputusan Setiap perilakuku adalah kebenaran Verse 2

Aku bicara kau yang mendengarkan Aku yang mau kau yang sediakan Aku perintah kau yang laksanakan Ooo.....

Verse 3

Setiap kemauanku adalah keputusan Setiap perilakuku adalah kebenaran Chorus

Darah tubuhku lain denganmu

Jangan pernah berpikir setara denganku (4x)

Aku satu-satunya $(4 \mathrm{x})$

3. "Satu"

Tempo $\quad: 130 \mathrm{bpm}$

Sukat $\quad: 4 / 4$

Durasi $\quad: 4.50$ menit

Lirik :

Verse 1

Terlihat bayang wajah murung

Dalam himpit sebuah harapan

Lirih terdengar sebuah bisikan

Jeritan tangis merintih mengiba

Verse 2

Hooo... hidup ini terasa hampa ketika kau tak ada

Hooo... nafas ini tersedak sesak

Jantung ini tak berdetak sempurna

Chorus

Tak mungkin aku bahagia disela meriah pesta Tak mungkin aku bahagia walaupun aku di surga

Kembali ke verse 2 dan chorus

4. "Penjara Emas"

$\begin{array}{ll}\text { Tempo } & : 72 \mathrm{bpm} \\ \text { Sukat } & : 4 / 4 \\ \text { Durasi } & : 6.35 \text { menit } \\ \text { Lirik } & :\end{array}$

Verse 1

Terpasung dalam sebuah mewah

Terbelenggu dalam sebuah megah

Mendekam dalam penjara dibalik emas

Hampa terkurung

Tersiksa dalam sekap, teraniaya

Verse 2

Tak kusangka menjadi lara

Kasih mesra tergoyah musibah

Kuambil langkah remehkan garis merah
Kulanggar perintah

Tersiksa dalam sekap, teraniaya

Chorus

Dengan paksa tak mungkin tercipta cinta

Dengan harta tak mampu membeli cinta $(2 x)$

Teraniaya dalam sekap, teraniaya

5. "Hanoman Obong"

Tempo : $: 210 \mathrm{bpm}$

Sukat $\quad: 4 / 4$

Durasi $\quad: 6.43$ menit

Lirik :

Verse

Harus pedang yang tak pernah kenal kasihan

Datang menyerang dalam gelap

Nafsu memburu layaknya hantu

Rakus serakah tak pandang bulu

Chorus

Adalah pantang bagi satria untuk gentar

Melawan tirani batil durjana

Adalah hina bagi manusia untuk buta

Acuhkan ketidakadilan merajalela

6. "Petuah yang Dianggap Sampah"

Tempo : $190 \mathrm{bpm}$

Sukat $\quad: 6 / 8$

Durasi $\quad: 6.35$ menit

Lirik :

Verse 1

Pemikiran yang telah dikacaukan

Harapan yang tak laksana tak semua mampu menerima

Bagai kalimat yang suci telah salah diterjemahkan

Laksana kepercayaan yang telah dihancurkan

Chorus 1

Bagai tahta kemasyuran yang dilecehkan

Kau pilih kalimat sesat yang terdengar nikmat

Daripada kalimat pahit yang kan luruskan

Datanglah gelap

Verse 2

Api dan senjata hebat tak akan pernah punya siasat

Tapi bahaya yang berat datang dari mulut sang penjilat

Chorus 2

Bagai bertulang kawat berotak tumpul

Bagai berotot besi bermuka tembok

Bagai berlimpah harta perilaku hina

Jika lihat tak cermat dan memburu hasrat

Sobat dan kerabat bisa menjadi jerat 
Datanglah gelap

Verse 3

Harus dikatakan semua kecewa ataupun suka

Karena berlaku darma cara satu menuju surga

7. “Eling lan Waspada"

Tempo $\quad: 100 \mathrm{bpm}$

Sukat $\quad: 4 / 4$

Durasi $\quad: 5.46$ menit

Lirik :

Verse 1

Buat apa guna kalian berperang

Jika kalian tak tahu artinya

Kalian berperang boleh-boleh saja

Kalau kalian semua tahu tujuannya

Verse 2

Tahukah siapa yang dibela

Tahukah maksud yang dituju

Apakah dia juga memperdulikanmu

Verse 3

Seberapa pantaskah dia untuk dibela

Cukup layakkah dia untuk dibela

Mampukah dia membayar pengorbanan

Seberapa hebatkah untuk dibanggakan

Kembali ke Verse 2

Chorus

Eling lan waspada (4x)

8. "Gerhanamu"

Tempo : $146 \mathrm{bpm}$

Sukat $\quad: 4 / 4$

Durasi : 4.46 menit

Lirik :

Verse 1

Dengan nafsu iblis menguasai jiwa

Menanam tunas nista gila angkara

Mengundang murka mala petaka

Menuai gerhana pasti kan tiba

Verse 2

Penguasa tak berarti miliki semua

Rampas tak pedulikan tangis ronta

Harusnya tak lukai dirimu sendiri

Dan kini sesal sudah tak berarti lagi

\section{Chorus}

Saat waktunya

Tak ada celah untuk sembunyi

Saat waktunya

Tak ada lagi tempat berlari

9. "Impas"

$\begin{array}{ll}\text { Tempo } & : 126 \mathrm{bpm} \\ \text { Sukat } & : 4 / 4 \\ \text { Durasi } & : 2.50 \text { menit } \\ \text { Lirik } & : \\ \text { Verse 1 } & \end{array}$

Alam punya cara untuk menghakimi

Bisa saja merasa benar dengan permainan cara pandang memutar fakta

Mata hati dibuang pergi dengan tak peduli

harga diri diinjak mati

Tak mungkin (3x)

Semua pasti impas

Verse 2

Bukan menjadi hal sulit

Untuk bisa tentukan arah jika sudah tau tujuan

Hanyalah cuma niat tuk kuat dan tekad

Untuk mampu bisa lakukan semua (tak mungkin 9x)

Waktu yang akan menjawab manisnya dosa

Waktu yang akan menjawab pahitnya perjuangan (3x)

Chorus

Alam punya cara untuk menghakimi (2x)

10. "Mandi Api"

Tempo $\quad: 78 \mathrm{bpm}$

Sukat $\quad: 6 / 8$

Durasi : 5.44 menit

Lirik :

Verse

Akan kau terima kebanggaan atas diriku Aku bersumpah padamu aku mencintaimu Akan terlihat kesucian di penglihatanmu Jangan menyerah padaku aku mencintaimu Bridge

Jangan merasa ragukan masa lalu kelabu

Yakinkan tak sia-sia perjuanganmu

Chorus

Dalam kobar mandi api

Akan jadi bukti tulus kesetiaanku tak ternoda

Dalam bara mandi api

Akan terlihat janji suci kan untuk selamanya

Kembali ke bridge

11. "Sigaraning Nyawa"

Tempo : $140 \mathrm{bpm}$

Sukat $\quad: 4 / 4$

Durasi : 5.54

Lirik :

Verse 1 (Rama)

Jingga diwajahmu laksana bias purnama 
Hangat mengisyaratkan beribu kerinduan Akhirnya terjawab segala risau hatiku Hati bahagia telah menemukanmu Verse 2 (Shinta)

Ujung cerita cinta tak lagi jadi tanya Terjawab semua dalam pelukan pertemuan Akhirnya terendap semua lara dijiwa Hati bahagia telah menemukanmu Chorus (Rama dan Shinta) Jadikan semua cerita lara sebagai untaian makna Susun kembali langkah baru dengan segala nilainya

Bridge

Bersama arungi bahtera

Bersama jalani asmara

\section{Kesimpulan}

Keseluruhan rangkaian komposisi musik "Towards Gamelan Pop" adalah sebuah kritikan sosial akibat permasalahan yang sedang populer di negara ini. Dengan memadukan musik pop dengan gamelan serta kisah pewayangan diharapkan akan semakin mudah diserap oleh masyarakat dan identitas negara tidak hilang dan juga untuk menarik minat generasi muda agar lebih mencintai budaya dan kesenian yang ada di negara kita.

\section{Kepustakaan}

Ismayanti. 2004. Pengantar Pariwisata. Jakarta. Grasindo.

Lal, P. 1981. Ramayana. Bogor.Dunia Pustaka Jaya. Mack, Dieter. 1995. Musik Populer. Yogyakarta. Yayasan Pustaka Nusatama

Prier, Karl-Edmund. 1996. Ilmu Bentuk Musik. Yogyakarta. Pusat Musik Liturgi.

2009. Kamus Musik. Yogyakarta. Pusat Musik Liturgi.

Shindunata. 1983. Anak Bajang Menggiring Angin. Jakarta. Gramedia.

Sukerta, Pande Mande. 2011. Metode Penyusunan Karya Musik. Surakarta-Solo . ISI Press Solo.

\section{Narasumber}

Rahayu Supanggah, Guru besar jurusan karawitan dan dosen pascasarjana ISI Surakarta. 